\title{
Hybrid Nanoparticles Inhibit Growth of Human Prostate Cancer Cells by Induction of Apoptosis
}

\author{
Yuji Komizu, Toshiko Ueoka, Mamiko Yukihara, Hideaki Ichihara, Yoko \\ Matsumoto and Ryuichi Ueoka* \\ Division of Applied Life Science, Graduate School of Engineering, Sojo University, Japan
}

Received: August 12, 2014, Accepted: September 26, 2014, Published: October 08, 2014

*Corresponding author: Ryuichi Ueoka, Professor, Division of Applied Life Science, Graduate School of Engineering, Sojo University, 4-22-1 Ikeda, Kumamoto 860-0082, Japan, Tel: +81-96-326-3952; Fax: +81-96-326-0522; E-mail: ueoka@life.sojo-u.ac.jp

\begin{abstract}
Hybrid liposomes (HL) can be prepared by simply ultrasonicating a mixture of vesicular and micellar molecules in buffer solutions, and contain no organic solvent unlike conventional liposomes. HL have remarkable inhibitory effects on the growth of various tumor cells including leukemia, lymphoma and colorectal cancer along with apoptosis in vitro, in vivo and clinical applications. In this study, we examined the inhibitory effects of HL the growth of human prostate cancer (DU145 and PC-3) cells in vitro. HL composed of $\mathrm{L}$ - $\alpha$-dimyristoylphosphatidylcholine (DMPC) and polyoxyethylene (25) dodecyl ethers $\left(\mathrm{C}_{12}(\mathrm{EO})_{25}\right)$ having nano-sized liposomal particles were produced. Markedly inhibitory effects of HL on the growth of DU145 and PC- 3 cells were obtained for the first time. It is noteworthy that HL induced apoptotic death of DU145 and PC-3 cells through activation of caspase-3. This study suggests that HL could be a promising novel agent for the treatment of prostate cancer.
\end{abstract}

Keywords: Hybrid Liposome; Nanomedicine; Dimyristoylphosphatidylcholine; Prostate Cancer; Growth Inhibition; Apoptosis; Caspase-3

\section{Introduction}

Prostate cancer occurs when malignant cells form in the tissues of prostate. Hormone therapy, also known as androgen deprivation therapy, can be used to treat prostate cancer after surgery or radiation therapy [1]. However, hormone therapy alone does not eradicate prostate cancer and metastatic prostate cancer does not respond to hormone therapy or chemotherapy [2]. Thus, the development of a new chemotherapeutic agent for prostate cancer is urgently needed $[3,4]$.

Hybrid liposomes (HL), first developed by Ueoka et al. [5], can be prepared by simply ultrasonicating a mixture of vesicular and micellar molecules in buffer solutions, and contains no organic solvent unlike conventional liposomes. The physiological properties of these liposomes such as size, shape, and the membrane fluidity can be controlled by changing the constituents and compositional ratios. The therapeutic effects of HL composed of L- $\alpha$-dimyristoylphosphatidylcholine (DMPC) and polyoxyethylene(20) sorbitan monolaurate (Tween 20) including antitumor drugs such as 1,3-bis(2-chloroethyl)-1nitrosourea (BCNU) have been observed on the growth of glioma cells in vivo [6]. On the other hand, HL composed of DMPC and polyoxyethylene(n)dodecyl ethers $\left(\mathrm{C}_{12}(\mathrm{EO})_{\mathrm{n}}\right)$ without any drugs have remarkable inhibitory effects on the growth of various tumor cells including leukemia, lymphoma and colorectal cancer along with apoptosis in vitro [7], in vivo[8,9] and clinical applications[10,11].

In this study, we examined the inhibitory effects of hybrid liposomes (HL) composed of DMPC and $\mathrm{C}_{12}(\mathrm{EO})_{25}$ on the growth of human prostate cancer cells in vitro.

Hybrid liposomes (HL) are nanosized liposomal particles (Figure $1 \mathrm{~A}$ ) and can be prepared by sonication of a mixture containing $90 \mathrm{~mol} \%$ DMPC (NOF, Japan) and $10 \mathrm{~mol} \% \mathrm{C}_{12}$ (EO) ${ }_{n}(n=25$ : Nikko Chemicals, Japan) in $5 \%$ glucose solution as described previously [12]. The liposomes composed of DMPC alone (DMPC liposomes) were prepared in the same manner as described above. The sample solutions were sterilized using a membrane filter with $0.20 \mu \mathrm{m}$ pore size. Figure 1B shows the time course of the hydrodynamic diameter $\left(d_{\mathrm{hy}}\right)$ change for HL using an electrophoretic light scattering spectrophotometer (ELS-Z, Otsuka Electronics, Osaka, Japan). The mean $d_{\text {hy }}$ of HL was about $33 \mathrm{~nm}$ in diameter with a single and narrow distribution and was stable for 35 days, though $d_{\text {hy }}$ of DMPC liposomes gradually increased with time. It is worthy to note that HL having size under $100 \mathrm{~nm}$ in diameter could avoid the reticular endothelial system in vivo [13] and thus should be appropriate for the intravenous administration in vivo and clinical applications.

First, we examined the $50 \%$ inhibitory concentration $\left(\mathrm{IC}_{50}\right)$ of HL on the growth of human prostate (DU145 and PC-3) cancer cells with WST-8 assay [12-14]. The cells $\left(5.0 \times 10^{4}\right.$ viable cells/ $\mathrm{ml}$ ) were seeded into 96 well plates and incubated for $48 \mathrm{hrs}$ in humidified $5 \% \mathrm{CO}_{2}$ at $37^{\circ} \mathrm{C}$ in the presence or absence of $\mathrm{HL}$. Subsequently, the WST-8 solution (Dojindo Laboratories, Japan) was added to each well. After $3 \mathrm{hrs}$, the absorption at $450 \mathrm{~nm}$ was measured with VersaMax Microplate Reader (Molecular 
A

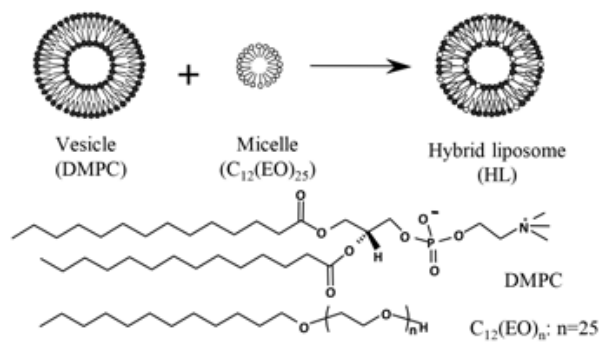

$\mathrm{C}$

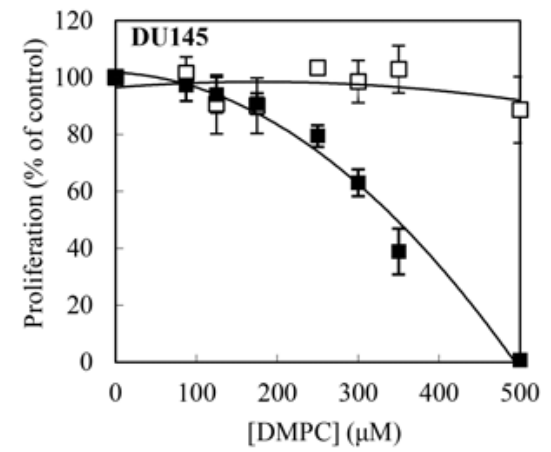

$\mathrm{B}$

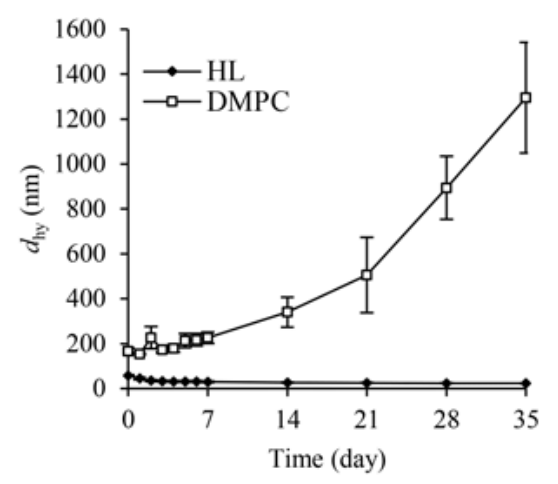

D

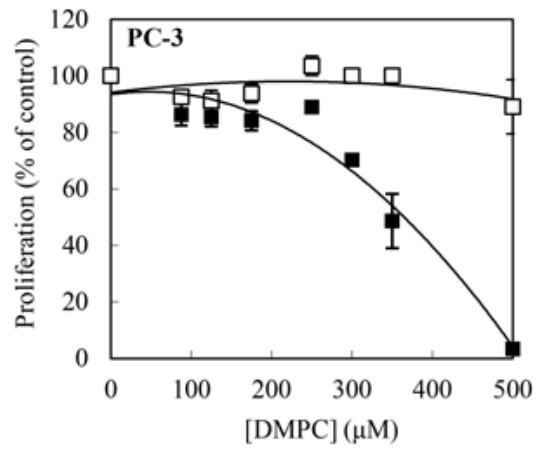

Figure 1: Hybrid nanoparticles showed anti-proliferation activity in prostate cancer cells.

(A) Schematic representation of hybrid liposomes (HL) composed of $90 \mathrm{~mol} \% \mathrm{DMPC}$ and $10 \mathrm{~mol} \% \mathrm{C}_{12}(\mathrm{EO})_{25^{\circ}}$ (B) Time course of hydrodynamic diameter $\left(d_{\text {hy }}\right)$ change for HL and DMPC liposomes at $25^{\circ} \mathrm{C}$. Error bars indicate S.E. for 4 individual experiments. [DMPC] $=10 \mathrm{mM},\left[\mathrm{C}_{12}(\mathrm{EO})_{25}\right]=1.1$ mM. (C), (D) HL inhibited the growth of DU145 and PC-3 cells for 48 hrs. a: HL; $\square$ :DMPC, Data represent the mean (n=3) \pm S.E.

Devices, CA, USA). The $\mathrm{IC}_{50}$ values of HL were determined from the concentration-dependency of HL on the cell viability (Figure 1C, D). The results are summarized in Table 1 . The $\mathrm{IC}_{50}$ values of HL were lower than those of DMPC liposomes in the growth of DU145 and PC-3 cells. These results indicate that HL could be effective for inhibiting the growth of prostate cancer cells.

We next examined the induction of apoptosis by HL in prostate cancer cells with a confocal laser scanning microscope using TUNEL method $[12,15]$. The results are shown in Figure 2A. The nuclei of all cells were stained by TOPRO- 3 and exhibited red fluorescence. We observed DNA fragmentation of prostate cancer cells when treated with HL for 48 hrs. In regard to the TUNEL staining, green or yellow (overlay) fluorescence was observed in cells treated with $\mathrm{HL}$, indicating the presence of nuclear condensation and fragmentation in apoptotic cells. In contrast, green (or yellow) fluorescence in the cells was not observed in the case of DMPC liposomes. These results demonstrated that HL could induce apoptosis toward prostate cancer cells. With the concentration employed in our experiments, contribution extent of $\mathrm{C}_{12}(\mathrm{EO})_{25}$, the second component of HL, to apoptosis signaling may be limited $[16,17]$, because $C_{12}(E 0)_{25}$ has been primarily considered to function for vesicle -fluidity and -uptake into cells $[18,19]$.

We further analyzed the DNA contents of HL-treated cells by flow cytometry, which can detect the apoptotic cells $[12,20]$.
The cells $\left(5 \times 10^{4}\right.$ cells $\left./ \mathrm{ml}\right)$ were seeded in 6 well plates and left to adhere overnight. The cells were then incubated for $48 \mathrm{hrs}$ in the presence or absence of HL. Then, the cells were washed with phosphate-buffered saline (PBS), resuspended in PBS containing $0.1 \%$ Triton X-100, treated with RNase A, and stained with propidium iodide (PI) (Molecular Probes, CA, USA). The DNA content of each cell was measured using a flow cytometer (Epics XL system II, Beckman Coulter, CA, USA). The treatment with HL induced a significant increase in the apoptotic DNA rate in DU145 and PC-3 cells (Figure 2B, C), indicating that HL induced apoptotic cell death in both cells. These results show that the inhibitory effects of HL were attained through the induction of apoptosis in the prostate cancer cells.

To investigate the apoptotic pathways induced by HL on DU145 and PC-3 cells, activation of caspase- 3 by HL was examined using PhiPhiLux $-G_{1} D_{2}$ substrate [21]. The results are shown in Figure 2D. It is worth noting that fluorescent intensity increased and cancer cells were dyed in green after the treatment with HL, indicating that HL induced apoptosis for prostate cancer cells through the activation of caspase-3.

In conclusion, HL inhibited for the first time the growth of DU145 and PC-3 human prostate cells through the induction of apoptosis in vitro. This study suggests that HL could be a promising novel nanomedicinal agent for the treatment of prostate cancer. 

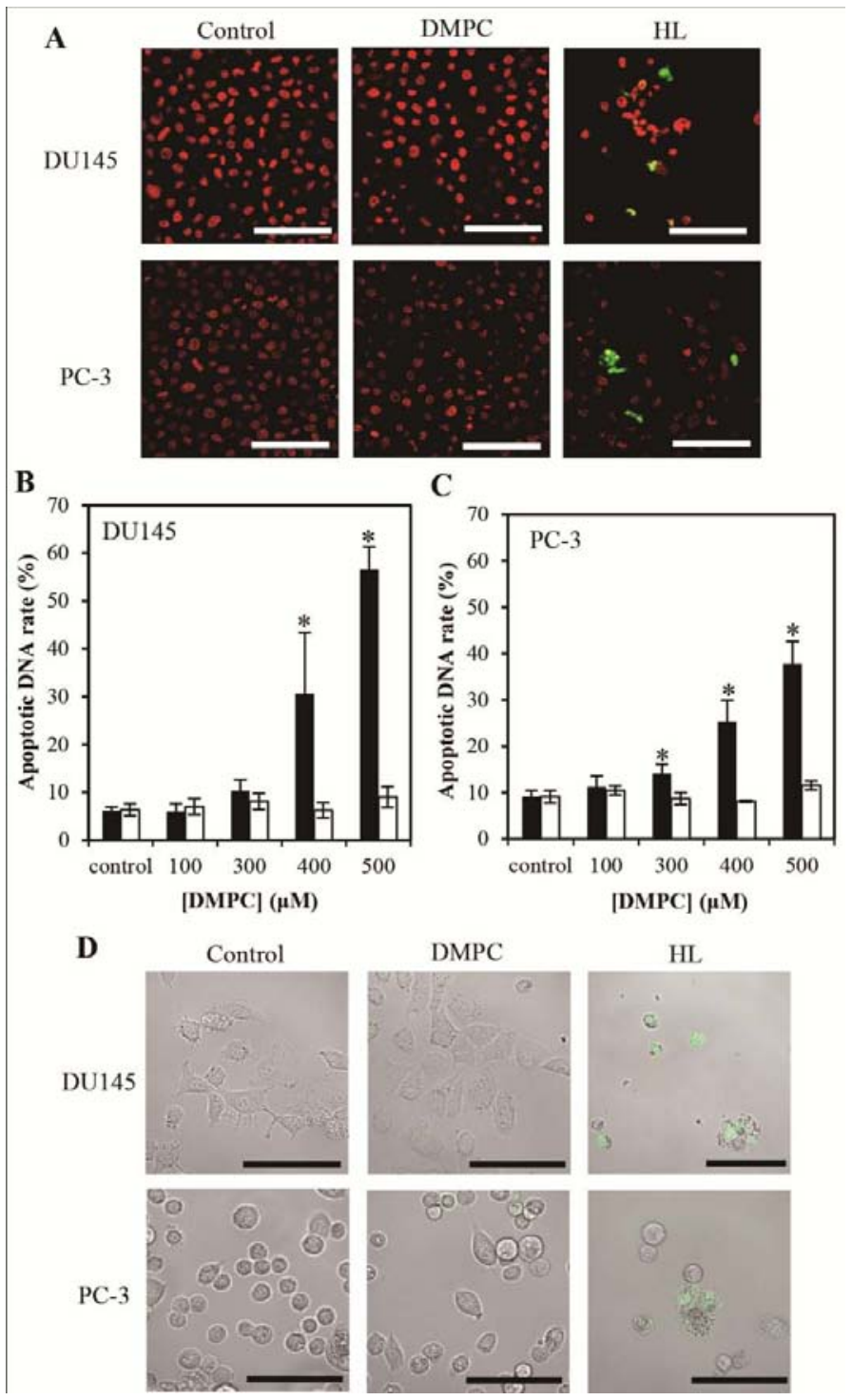

HL
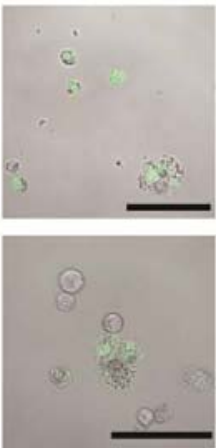

Figure 2: Induction of apoptosis in prostate cancer cells by HL.

(A) Fluorescence micrographs of DU145 and PC-3 cells treated with HL for 48 hrs using TUNEL method. [DMPC] $=400 \mu$ M. Scale bar: $100 \mu \mathrm{m}$. Apoptotic DNA rate of DU145. (B) and PC-3 cells (C) treated with HL for 48 hrs. $\mathbf{m}$ : HL; $\square$ : DMPC, Data represent the mean (n= 3-5) \pm S.E. Significantly different from control with $p<0.05(*)$ calculated by Student's $t$-test. (D) Fluorescence micrographs of DU145 and PC-3 cells stained with PhiPhiLux (green: active caspase-3) after the treatment with HL for $48 \mathrm{hrs}$. [DMPC] $=400 \mu \mathrm{M}$. Scale bars: $100 \mu \mathrm{m}$.

Table 1: $50 \%$ Inhibitory concentration $\left(\mathrm{IC}_{50}\right)$ of $\mathrm{HL}$ on the growth of DU145 and PC-3 cells.

\begin{tabular}{|c|c|c|c|}
\hline \multicolumn{4}{|c|}{ IC $_{50}[\mathbf{D M P C}] \boldsymbol{\mu M}$} \\
\hline \multicolumn{2}{|c|}{ DU145 } & \multicolumn{2}{c|}{ PC-3 } \\
\hline DMPC & HL & DMPC & HL \\
\hline $639 \pm 23$ & $325 \pm 15$ & $759 \pm 43$ & $331 \pm 25$ \\
\hline
\end{tabular}

Data are the mean \pm S.E. $(n=4)$ from three independent experiments.

\section{Acknowledgments/Disclosures}

This work was supported in part by a Grant-in-Aid for Science Research from the Ministry of Education, Culture, Sports, Science and Technology of Japan (Nos. 25289299 and 24656509).
The authors declare no conflict of interest associated with this manuscript.

\section{References}

1. Sasse AD, Sasse E, Carvalho AM, Macedo LT. Androgenic suppression combined with radiotherapy for the treatment of prostate adenocarcinoma: a systematic review. 2012; 12: 54. doi:10.1186/1471-2407-12-54.

2. Shelley M, Harrison C, Coles B, Staffurth J, Wilt TJ, Mason MD. Chemotherapy for hormone-refractory prostate cancer. Cochrane Database Syst Rev. 2006; 4:CD005247.

3. Amaral TM, Macedo D, Fernandes I, Costa L. Castration-resistant prostate cancer: mechanisms, targets, and treatment. Prostate Cancer. 


\section{2; 2012:327253. doi: 10.1155/2012/327253.}

4. Higano CS, Crawford ED. New and emerging agents for the treatment of castration-resistant prostate cancer. Urol Oncol. 2011;29(6 Suppl):S1-8. doi: 10.1016/j.urolonc.2011.08.013.

5. Ueoka R, Matsumoto Y, Moss RA, Swarup S, Sugii A, Harada K, et al. Membrane matrix for the hydrolysis of amino acid esters with marked enantioselectivity. J Am Chem Soc. 1988; 10(5):1588-95. doi: 10.1021/ja00213a035.

6. Kitamura I, Kochi M, Matsumoto Y, Ueoka R, Kuratsu J, Ushio Y Intrathecal chemotherapy with 1,3-bis(2-chloroethyl)-1-nitrosourea encapsulated into hybrid liposomes for meningeal gliomatosis: an experimental study. Cancer Res. 1996; 56(17):3986-92.

7. Matsumoto Y, Iwamoto Y, Matsushita T, Ueoka R. Novel mechanism of hybrid liposomes-induced apoptosis in human tumor cells. Int J Cancer. 2005; 115(3):377-82.

8. Ichihara H, Hino M, Umebayashi M, Matsumoto Y, Ueoka R. Intravenous injection of hybrid liposomes suppresses the liver metastases in xenograft mouse models of colorectal cancer in vivo. Eur J Med Chem. 2012; 57:143-48. doi: 10.1016/j.ejmech.2012.08.040.

9. Komizu Y, Yukihara M, Ueoka T, Ichihara H, Matsumoto Y, Okada S et al. Therapeutic effects of hybrid liposomes for mouse models of adult T-cell leukemia/lymphoma in vivo. Nano Bull. 2012; 1(1):120105.

10. Ichihara H, Nagami H, Kiyokawa T, Matsumoto $Y$, Ueoka R. Chemotherapy using hybrid liposomes along with induction of apoptosis. Anticancer Res. 2008; 28(2B):1187-95.

11. Ueoka R, Matsumoto Y, Goto K, Ichihara H, Komizu Y. Membrane targeted chemotherapy with hybrid liposomes for tumor cells leading to apoptosis. Curr Pharm Des. 2011; 17(17):1709-19.

12. Komizu Y, Nakat S, Goto K, Matsumoto Y, Ueoka R. Membranetargeted nanotherapy with hybrid liposomes for tumor cells leading to apoptosis. ACS Med Chem Lett. 2011; 2(4): 275-79. doi: 10.1021/ ml100269t
13. Huang SK, Lee KD, Hong K, Friend DS, Papahadjopoulos D. Microscopic localization of sterically stabilized liposomes in colon carcinomabearing mice. Cancer Res. 1992; 52(19):5135-43.

14. Tominaga H, Ishiyama M, Ohseto F, Sasamoto K, Hamamoto T, Suzuki $\mathrm{K}$, et al. A water-soluble tetrazolium salt useful for colorimetric cell viability assay. Anal Commun. 1999; 36:47-50. doi: 10.1039/ A809656B.

15. Gavrieli Y, Sherman Y, Ben-Sasson SA. Identification of programmed cell death in situ via specific labeling of nuclear DNA fragmentation. J Cell Biol. 1992; 119(3):493-501.

16. Nakano K, Iwamoto Y, Takata W, Matsumoto Y, Ueoka R. Specific accumulation and growth inhibitory effects of hybrid liposomes to hepatoma cells in vitro. Bioorg Med Chem Lett. 2002;12(22):3251-54.

17. Iwamoto Y, Matsumoto Y, Ueoka R. Induction of apoptosis of human lung carcinoma cells by hybrid liposomes containing polyoxyethylenedodecyl ether. Int J Pharm. 2005; 292(1-2):231-39.

18. Komizu Y, Matsumoto Y, Ueoka R. Membrane targeted chemotherapy with hybrid liposomes for colon tumor cells leading to apoptosis. Bioorg Med Chem Lett. 2006; 16(23):6131-34.

19. Nagami H, Matsumoto Y, Ueoka R. Chemotherapy with hybrid liposomes for lymphoma without drugs in vivo. Int J Pharm. 2006; 315(1-2):167-72.

20. Nicoletti I, Migliorati G, Pagliacci MC, Grignani F, Riccardi C. A rapid and simple method for measuring thymocyte apoptosis by propidium iodide staining and flow cytometry. J Immunol Methods. 1991; 139(2):271-79.

21. Komoriya A, Packard BZ, Brown MJ, Wu ML, Henkart PA. Assessment of caspase activities in intact apoptotic thymocytes Using cell-permeable fluorogenic caspase substrates. J Exp Med. 2000; 191(11):1819-28. 